\title{
The Role of Embedded Individual Values, Belief and Attitudes and Spiritual Capital in Shaping Everyday Postsecular Organizational Culture
}

\section{Abstract}

This paper investigates the values, beliefs and attitudes (VBA) held by individual employees within business environments which motivate and shape behaviour in the workplace, and the extent to which VBA reveal roots and drivers linked to spiritual capital (and associated capitals). Building on early authorial work (Authors, 2011), and referring to literature from theology and religion, as well as business organization and management, the paper discusses the critical and dialectical relationship between different forms of capital (for example, social, human, economic), modernistic, 'hard' cultures and issues of managerialism and alternative critical, 'soft' frameworks and sources of ethics and values - and their impact on the business setting. It will do this primarily by proposing a new typological model showing the dynamic and potentially progressive interplay between spiritual, human, bridging and linking forms of social capital within corporate and public settings and explores their implications for management. This typological model is derived from original research using in-depth semi-structured interviews from three different organizations in NW England and Wales, to determine the extent to which notions of the postsecular and spiritual capital may operate in workplaces.

Key Words: Values, Beliefs, Attitudes, (VBA), Social Capital, Postsecular, Spiritual Capital.

\section{Introduction}

The primary aim of this paper is to consider the significant ways in which the Values, Beliefs and Attitudes (VBA) of individuals shape the material expression and the ethos of corporate business settings. We suggest that whilst VBA is often occluded from public view (for reasons of both personal 
reticence and modesty, but also the perceived edict against the public expression of religious or spiritual belief in the workplace), it nevertheless can have a powerful and significant effect in democratising and humanising the corporate setting by motivating actions in relation to the public fabric of a particular work context.

Thus, the practical implementation of VBA may be both subversive of, and conducive to, the espoused ethos of the official corporate setting. It is a vital expression of spiritual capital that creates and amplifies existing levels of business social capital (especially in terms of increasing levels of trust both within and across business-client relationships, reinforcing progressive normative behaviours and creating and sustaining social and collaborative networks by which individual workers feel they 'belong' and have a valuable contribution to make). This context produces the following research question:

In which ways are the facets, dimensions and impacts of VBA and spiritual capital manifested and operationalised in the context of everyday business situations?

\section{Literature Review}

\section{Values, beliefs and attitudes in organizations: normative and everyday perceptions.}

The thrust of this research resonates the words of Andre Malraux's poignant assertion made over fifty years ago that 'le XXI siècle sera spirituel ou il ne sera pas' (sic: 'the $21^{\text {st }}$ Century will be spiritual or it will not be'). Malraux's statement, set against the immediate backdrop of Second World War destruction, resultant Cold War ideologies and the threat of nuclear Armageddon was a stark call for novel approaches and new ways of thinking to address old ideologies. In a contemporary context, the spirit of Malraux's assertion is also in the process of being actively explored across a range of disciplines including politics, business 
and economics (see for example, Zohar and Marshall, 2004; Lee, Lovelace and Manz, 2013).

Our argument draws primarily on a business, management and organization theoretical framework. However, the realm of VBA clearly readily traverses a range of disciplinary and epistemological boundaries and, therefore, by employing the various knowledge(s) of the interdisciplinary research team associated with the paper, the argument also contributes an interface with the concepts of the secular, postsecular, social and spiritual capital (charting their interaction and impacts within the site of 'the organization', and the management of organizations) which stem from business, political philosophy and sociology. This synthesis provides novel insights and development of the theoretical understanding of VBA in management and organizational contexts.

\section{Social Capital and Human Capital - extrapolating the links}

One of the overarching ideas in business literature on social capital and human capital is that the development of leadership is dependent on the availability of both human capital (the knowledge and skills that an individual brings to the workplace) and social capital (the relationships between individuals and organizations that facilitate action and create value) (Hitt and Ireland, 2002). Whereas Kaufman and Geroy (2007) define a clear relationship between the capitals: "Social capital, a form of human capital, refers to the connections, or social networks, among individuals" (p.39), Barros (2006) sees them as competing theories and states that "human capital is more important than social capital" (p.15). This privileging of human capital over other forms of capital is a product of a longstanding and hegemonic modernistic (scientifically and positivistically underpinned) organizational imperative and predilection by management and organizations for the reification and attainment of heightened notional 'targets', 'effectiveness' and 'performance' while paying lipservice to other human capacities, needs, values and ethics (as long as they subtend modernistic goals) (Stokes, 2011). The dominant presence of 
theoretical modernistic structures over much of human capital invokes a tension between competing critical perspectives, theoretical (for example, sociological, postmodern) foundations and complementary capitals. Nevertheless, in the current post-recession environment, there is much scope for organizations to develop social capital or face human capital switching jobs in search of better working conditions elsewhere.

The development of social capital theory focuses on the subset of resources that an individual could access, not through their own inheritance or acquisition, but through interaction with others (Lin, Cook and Burt, 2001). These interactions - or networks of relations - are central to the development of capital; they and the resources they bring to the individual, comprise "personal connections, enhanced knowledge and wherewithal and inside information" (Anderson, 2010, p.3). In social capital theory, therefore, the interactions or networks are fundamental in enabling social capital affairs to be conducted and benefit network members. It is the social capital (or assets) that are embedded in those relationships that can contribute to developing value outcomes (Dess and Shaw, 2001). In essence, this also infers that an enriched understanding of managerial and organizational culture and performance, in relation to various capitals, should encompass more than a surface adherence to human capital and its subscription to a somewhat disembodied and restrictive adherence to, for example, targets, cost and efficiency savings and key performance indicators.

Historically, social capital emerged as a concept of sociology and political theory towards the latter half of the 20th century (although the term originated in 1916). It has been argued that the interest in social capital has arisen from both the centre-left and the centre-right: either as a way of minimising the socially-atomising social impacts of neo-liberal capitalism that emerged in the mid-80s by reintroducing non-coercive forms of solidarity or as a means of enhancing the de-centralising thrust of the market with an appeal to personal values and virtues - the so-called 
'virtue-economy' debate (Baker 2012). Three classic exponents of the concept are Pierre Bourdieu, James Coleman and Robert Putnam. Bourdieu sees the concept from a Marxist perspective. Social capital is an expression of cultural capital (or class) with the elite (upper-class) reproducing the necessary means of access to culture and education that maintains their pre-eminence. Social capital is thus associated with 'honourability and respectability' (Bourdieu, 1997: 503) which allows one to capitalise or acquire more social standing in society thus boosting access to networks of influence and power. For Coleman, social capital is derived not so much from class as education and family life. At their best, these components produce a mutually reinforcing or virtuous cycle of capitals that enhance both cognitive and emotional development. Thus social capital for him are '[the norms], the social networks and relationships between adults and children that are of value for the child's growing up... Social capital exists within the family, but also outside the family, in the community (quoted Field, 2003: 24). Robert Putnam develop Coleman's thinking around social capital existing in community networks to look more at the communitarian rather than individual impacts of social capital. Its real value, he argues, lies in networks which affect the productivity of individuals as productive citizens by embedding them within social connections: "social networks, and the norms of reciprocity and trustworthiness that arise from them" (2000: 19).

Putnam is also well-known for differentiating different types of social capital, some of which this article uses as part of its evidence base for the often hidden but also pervasive impact of spiritual capital on the corporate and work-based environment. His basic typology consists of two types of social capital: bonding capital and bridging capital. Bonding social capital he defines as 'inward looking [networks that] tend to reinforce exclusive identities and homogeneous groups' (Putnam, 2000:22). Bridging capital in contrast is defined as open networks that are 'outward looking and encompass people across diverse social cleavages' (Putnam 2000). Putnam likens their social function with two memorable analogies. Bonding social capital which tends to 
give communities and groups an inner cohesiveness and resilience is likened to 'superglue', while bridging forms of capital lubricate the wider purposes civil society like a 'sociological WD 40' (Putnam 2000: 23). A third typology - 'linking' social capital was included, partly in response to the perceived lack of power analysis in Putnam's work. Devised by Michael Woolcock, it refers to the capacity of weaker groups and communities to leverage 'resources, ideas and information from formal institutions beyond the community' (ONS 2001: 11). We develop these definitions of bridging and linking forms of social capital to reflect the virtues of seeking to smooth relationships and communication across different strata of the business organisation, as well as imparting knowledge and resources to vulnerable groups (clients, fellow employees) which emerged as practical expressions of spiritual capital in our research data.

These debates on social capital have since expanded into economic and management sciences. Although the concept has been criticised for recycling well-known fundamental theories and common sense, literature points to the increasingly important role played by social capital - and human capital - in leadership development and in the management of human resources (Akdere, 2005). More recently, the work of Leitch et al. (2013) explores how entrepreneurial leadership development can be seen as a social process; one of the key findings was that the enhancement of leaders' human capital only occurs through their development of social capital. Organizations are becoming gradually more aware of the importance of social interactions and relationships at work. The focus is on embedding social capital to foster, utilise and enhance the success of the organization. In the current era of sharing knowledge, social capital is of critical significance to organizational performance and productivity - and ultimately to sustainability. Consequently, organizations are now faced with the challenge of understanding social capital and its implications in the workplace.

\section{The Postsecular Public Sphere}

We have explored the correlations between social and human capital in public, managerial and organizational spheres. In particular, we have 
highlighted the frequently paradoxical dehumanising dimensions of more mechanistic modernistic human capital approaches in comparison with more critical and social capital appreciations. We now refine our conceptual framework to include discussions around the postsecular and spiritual capital. In earlier work, the authors outlined some of the emerging definitions and debates surrounding these terms and these are explored below (Authors, 2011). This work on the postsecular, traced the new public visibility of religion in all its forms towards the end of the $20^{\text {th }}$ century under the impact of new dynamics of digital, as well as material, processes of globalisation and the vacuum created by the collapse of the Soviet Empire (Tweed, 2006; Vasquez, 2011; Micklethwaite and Wooldridge 2009; Caryl, 2013).

This context led to substantive revision of theories on secularisation which had emerged in the middle of the $20^{\text {th }}$ century and which speculated that as the processes associated with modernity (i.e. the reification of sciencebased technological innovation and urbanisation) inexorably shaped contemporary life, so the power and authority of religion(s) (be they, for instance, Christianity, Hinduism, Islam, Judaism or any other denomination) would be increasingly relegated to private spheres. Thus, for example, Casanova (1994) referred to the de-privatisation of public sphere whereby religious traditions throughout the world refuse to accept the marginal and privatised role which theories of modernity had ascribed to them. Berger (1973) once defined secularisation as a process by which sectors of society and culture are removed from the domination of religious institutions and symbols. He now deploys the concept of desecularisation to describe the resurgence of furious, supernaturalist, fundamentalist or conservative expressions of religion (1999) in politics and public life. These socio-political trends, which have gathered pace as the $21^{\text {st }}$ century has progressed, led the Marxist-influenced social theorist and philosopher Jürgen Habermas to suggest the need to re-imagine the public sphere as postsecular one; i.e. a 'postsecular self-understanding of society as a whole, in which the vigorous continuation of religion in a 
continually secularizing environment (particularly in notional Christian orientated countries) must be reckoned with' (2005, p.26). This observation is not describing the replacement of secularisation within liberal democracies by a resurgent public expression of religion. Rather, it suggests that on-going dynamics of secularisation (as process) and secularism (as a normative cultural and political positon) now compete within the public sphere with some unexpected expressions of an emergent and confident religion. Religious beliefs and practices, and kindred values, far from being marginalised are present and active in many areas of public, managerial, organizational and private life.

A public policy discourse exploring the re-emergent and newly visible impacts of faith-based social care and welfare has meanwhile emerged as part of the social capital debate [as discussed above - see for example Dinham et al (2009), Beaumont and Cloke (2012), Local Government Association (2012)]. As discussed above, Putnam and others (see Halpern 2005 and Woolcock, 2001) have refined the communitarian impacts of social capital by distinguishing between bonding social capital which describes intra-group networking, bridging social capital describing horizontal linkages to other groups, and linking social capital which describes vertical relationships (through extant hierarchies) to centres of resources and power. These categories underline the rich range of ways in which social capital may be manifest and raises important questions and potential implications for organizations which have not hitherto paid sufficient attention to this phenomenon. In particular, in relation to spiritual and social capital, it is this nexus and dynamic between bridging and linking social capitals within organizational structures and hierarchies which may emerge as a result of the deeper operation of spiritual capital. The composite of these processes and structures provide a deeper form of 'unseen DNA' for the surface level modernistic understandings and operations of human capital and it is to the operation of these more profound structures to which the next phase of the argument turns. 


\section{Spiritual Capital}

Spiritual capital as it being deployed in this article, first emerged in the early 2000s from work undertaken by the William Temple Foundation to explain the enhanced and resilient forms of social capital created by faith communities in urban areas of high deprivation and poverty. The research suggested that spiritual capital 'energised' the practical contributions made by these groups by 'providing a theological identity and worshipping tradition, but also a value system, moral vision and a basis of faith. It is often embedded locally within faith groups, but also expressed in the lives of individuals'. (Baker and Skinner, 2006:7). This work has subsequently assessed the social capital-generating properties of secular spiritual capital across a number of other different settings associated with health and social care and planning (see Baker and Miles-Watson, 2008; Gilbert, 2011; Holloway, 2005; Sandercock, 2008).

In [Author article] (2011), we re-calibrated spiritual capital as a conceptual and analytical tool within the organizational and business environment thus:

Spiritual capital is the set of values, ethical standpoints and visions for change held by both individuals, groups and institutions. It is shaped not only by systems and practices of belief, but also by engagement with wider sets of relationships (broadly defined) and the sense of meaning and purpose derived from work-based and other activities (sometimes referred to as the 'spirit' or 'soul' of a business). Spiritual capital is often the source of motivation for other forms of capital (e.g. social capital and its emphasis on the importance of trust and norms as the basis for conducting any form of progressive or enhancing human activity). It includes.... how beliefs inform values... where we fit in... what we do.

Thus, we are proposing that the emergence of postsecularity in the public sphere has opened up a new series of 'spaces' through which to 
evaluate the salience of spiritual capital as a means of redefining the importance of norms and VBA in organizational and public life (Authors, 2011). Many of these debates on the role and contribution of religion and belief to ethics and public life, and including business and economics, have intensified since the 2008 financial crash (Skidelsky and Skidelsky, 2012; Sandel, 2012). The argument now progresses to relate the above notions of VBA as an expression of spiritual capital to business management and organizational contexts.

\section{Surfacing Spiritual Capital in Business Management and Organizational Theory}

Having introduced the device of bridging and linking capitals above in order to map out the dynamics of human, social and spiritual capitals within the site of 'the organization', the argument now considers a number of issues from directly within organization and management theory which inform and bolster conceptual frameworks relating to VBA and its relationship to spiritual (and indeed, other forms of) capital. These sources might typically incorporate, among others, for example: organizational behaviour, corporate culture, leadership, spirituality, business ethics or human resource management. This is a rich and complex set of domains and for the purposes of developing the argument, within the overarching framework of a modernistic-critical dialectic, the paper critically develops the dialectical relationship between 'hard' and 'soft' business cultures.

\section{Hard and Soft Business Cultures as sites of VBA}

As indicated above, normative, modernistic commentaries on corporate culture have tended to view culture as a tangible and palpable artefact, possessing clearly defined boundaries. Therein, the appropriate and 
successful management of corporate culture is seen as being grounded on 'modernistic' organizational imperatives such as efficiency, effectiveness, performativity, productivity and consequent profitability. The modernistic approach to culture tends to represent culture as comprising 'hard' and 'soft' dimensions. The 'hard' dimensions include logos, mission statements, corporate reports and documents, the style of buildings, dress codes, organizational structures, profit targets, performance and productivity procedures. Such 'hard' dimensions are intended to underline and overtly reinforce the espoused and disseminated corporate ethos of the company.

In contrast, soft 'dimensions' point towards attitudes, values, motivation, team spirit and organizational rituals (Lawrence and Jordan, 2009; Smith, Singal and Lamb, 2008). These are the sites where spiritual and social capitals might be considered as naturally residing. With a predominant and prevailing modernistic conceptualisation of organizational culture associated with Fordism and Taylorism (where the role of management is to ensure notions and objectives of efficiency, effectiveness and optimisation in relation to people, performance and profit) (Morgan, 2006), it is the 'hard' dimensions which tend to be privileged over the softer aspects. Nevertheless, in recent decades, the potential value of the 'soft' side of the firm including concepts such as human capital management theory, has been increasingly recognised by practitioners:

'... a treasure that a company or institution has available with respect to the qualifications of the personnel that works there. Therefore, human capital represents the value that each employee brings to the table, according to his/her studies, knowledge, capabilities and skills' (Deloitte: 2014).

Moreover, the direction of contemporary definitions of human capital management theory (Hartog and Maassan Van der Brink, 2009; BurtonJones and Spender, 2012; Joshua, 2105) may be considered a softening 
and popularising of the more scientific and empirical approaches offered by earlier theorists such as Becker (1964) who saw human capital as a more utilitarian and uni-dimensional 'stock of knowledge and skills' that directly and strategically enhanced the firm's profits. Such moves soften the harder edges of human capital theory and have aligned with a wide range of contemporary areas of theory and research including: teambuilding, coaching, mentoring, responsible management, sustainability, well-being at work and work-life balance, meaning and identity in work lives; faith, values, religion, spirituality, corporate governance, corporate social responsibility (CSR), responsible management, sustainability, wellbeing, commitment, transformational leadership and business ethics (Elizur, 1996; Fineman, 2000; Russell, 2001; Jaakson, 2010; Mostovicz, Kakabadse, and Kakabadse, 2011; Opdebeeck and Habisch, 2011; Blowfield and Murray, 2011; Ashkanasy, Härtel and Zerbe, 2012; Brammer and Pavelin, 2013). It has also been accompanied by a range of conferences examining these themes (for example, the Propedia Conference (2011) on the theme 'The return of the sacred in the company'). Within the normative organizational modernistic perspective, these 'soft' aspects are commonly co-opted to reinforce 'strong' corporate cultures with the expectation that employees are aligned to the organization's mission and values, resulting in high performance and profitability. Strong cultures contrast with 'weaker' corporate cultures where many employees are not aligned to the organizational mission and values, resulting in variable performance and profitability (Mayo, 1946; Deal and Kennedy, 1982; Schein, 1990; Kono and Clegg, 1998; Johnson and Duberley, 2011; Rishi and Moghe, 2013).

Critical perspectives offer critiques in response to these normative representations of culture (business or otherwise) employing, for example: social constructionism, discourse, resistance, power, sexuality, commitment and managerialism (Jermier, Knights and Nord, 1994; Alvesson, 2002; Badham et al., 2003; Linstead, Fulop and Lilley, 2009; Lee, Tan and Javalgi, 2010; Clegg, Kornberger and Pitsis, 2011; Stokes, 
2011; Urry and Larsen, 2011; Knights and Willmott, 2012; Hatch, 2013; Lee, Lovelace and Manz, 2013; Tenhiälä et al., 2013; Liviu, Cheung and Herndon 2013; Jeanes and Huzzard, 2014). Overall, these varying concepts suggest that individual and corporate VBA and cultures derive from a wide range of sources and are therefore ephemeral in nature, problematic to define and, hence, difficult to subject to managerial control. In other words, VBA tends to operate in dimensions that seem beyond the reach of conventional organizational and managerial techniques. Thus, Gabriel and Lang (2006) discuss the notion of 'unmanaged' and 'unmanageable' spaces in relation to individual beliefs and behaviour. A 'strong' or 'managerialist' culture may seek alignment and compliance from employees. However, in personal spaces, individual employees are guided by their own VBA in relation to purported organizational values, and in so doing, potentially subvert those values in independent and progressive ways. In summary, the evolution and strengthening of the 'soft' and critical perspectives on workbased/corporate culture and VBA-type matters has achieved a number of outcomes. Firstly, it has profiled and provided a range of subjects and discourses through which to better identify and surface the operation of social and spiritual capitals in organizations and management. Secondly, the overall evolution of the field has provided languages with which to explore the functioning of human, social and spiritual capitals through bridging and linking capitals within organizational and postsecular contexts. The argument now moves on to develop primary data in relation to these issues and the research question.

\section{Methodology}

The study was subject to ethical clearance and the fully informed participation of the companies and individuals concerned. Six organizations located in the North West of England and North Wales were purposively approached from an institutional database of convenience sample 'warm' and approachable contacts encompassing a broad 
spectrum of different sectors and businesses. Due to the nature of the study, this approach was felt necessary as access was challenging to negotiate. Three firms agreed to participate in the study: an IT and webdesign company; a regional legal firm and a Japanese-associated manufacturing enterprise (with employees and interviewees primarily from the local populace). The size of the companies ranged from 30 to 200 plus employees. An indicative sampling frame of employee roles and levels was provided to the companies and six interviewees were selected by each company to represent a full spectrum of positions within their firm, from senior management (including the CEOs), middle management, human resources and shop floor (or equivalent) operators. Semistructured interviews were conducted ranging from 20-40 minutes.

The data were manually analysed using Template Analysis (King, 2004a,b and King and Horrocks, 2010). The Template Analysis operated by undertaking intensive readings and re-readings of the data sets independently by two members of the research team. This process generated a number of a priori codes which constituted the initial broad themes standing out in the data. In the next stage, the data were examined in great detail with a view to identifying 'segments' of text which appeared to offer insight into the broad themes and research question. Segments which appeared to match a priori codes were immediately linked whereas segments which were less able to be connected automatically with a priori codes were assigned new a priori codes. The reading of three-four transcripts began to produce an early shape of the analytical template and this was reinforced an adjusted by subsequent interview readings (King, 2004 and following the practice models of McDowall and Saunders, 2010; Waring and Wainwright, 2008).

In addition, following the interview the participants were also invited to self-identify according to series of six questions on the participant's views and adherence to religion and belief. Possible answers to each of the six questions were laid out on a Likert Scale. The Likert Scale attached to 
each of the questions comprised four possible options with regard to religious or spiritual beliefs, for example: 'I would define myself as: Religious, Spiritual, Agnostic, Atheist. There were five further questions in this vein. The respondents were also asked to identify their gender designation, age (in deciles) and ethnicity according to the 2011 census classification of ethnicity.

The study was open to the collection of data on any religious denominations which presented within the data set. However, perhaps due to the some of the geographical area predominant characteristics, the reported data were exclusively Christian-based.

The reliability and validity of the data generation were reinforced by the dual team members Template Analysis coding of the data. The resultant coding was cross-referenced, verified and minor classification adjustments made where deemed appropriate. Prior to the study's interview schedule and the Likert Scale being employed with respondents, the research instruments were pilot tested in-house (university) and with allied company participants and the responses examined and moderated. Moreover, it is important to note that in engaging Template Analysis and Likert Scales, the study employs well-tried techniques which further enhances the reliability aspect of the research.

\section{Findings and Discussion}

The Likert Scale Self-Identification, Gender, Age and Ethnicity Designation. 
From the self-identity Likert Scale, four participants identified themselves with traits of the agnostic variable. Nine respondents identified themselves with a religious bracket and five respondents located themselves as exhibiting aspects of high spirituality. Seven of the sample identified themselves as have strong aspects of atheism. All of those respondents who declared some form of faith indicated that the faith was Christian-based rather than, for example, Hinduism, Islam or Judaism. Thus, the data indicated a spread of faith commitment. Nevertheless, there was overall an evident orientation towards the holding of beliefs or faith in some regard. This underscored the latent but active role of faith in relation to the spiritual and VBA aspects of the firm. Religious respondents were split between female and male and located across age groups with no particularly discernible trend. Equally atheists and agnostics were spread out through the sample. These findings pointed towards spiritual observation in the more profession-bound settings as opposed to the semi-skilled respondents. In a British context in which the research was conducted it may be that this was associated in some way to underlying cultural socio-economic factors although the determination of this would need to be focus of wider research.

\section{Emergent Major and Sub-Themes}

From the Template Analysis outlined above which was applied to transcripts the following four major themes emerged:

- Drivers of behaviour;

- Sources of VBA;

- Impact of VBA on individual and corporate behaviour;

- Negotiating and performing religious identities in the workplace.

These four themes will now be discussed in greater detail. 
The data identified four different drivers of behaviour within the work place. These drivers were termed: 'bottom-line'; 'employee satisfaction' (i.e. human capital driver); 'spiritual capital driver' and 'external dynamics which lie beyond the control of individuals and companies'.

The 'bottom line' or 'metrics' driver was aligned to the prevalence of corporate imperatives of performativity and profitability. This echoed the above-commented dominance of modernistic values within the workplace (Clegg, Kornberger and Pitsis, 2011; Stokes, 2011). This driver featured in several of the interviews across all three corporate settings. It reflected, for example, the extolled importance of focusing on 'client satisfaction' and optimising the 'bottom-line' results for the company in terms of profitability and growth targets:

'Revenue is really important - we're a business at the end of the day - but you want clients who want your services. We want to be needed by the client in order to retain the contract - it's important we retain the brands and create exposure for the company. Because that is what the general public see... It all does probably come down to the bottom line' (Respondent 5, Female, IT Firm, 36-45, Atheist).

Within this cluster of responses, financial incentives based on performance were also cited as a significant motivator. 'That element of achievement is obviously motivational - values have always been about performance. "Build, Promote, Perform": that is our strapline.' The dominance of this modernistic metric was strongly, although subconsciously, evident in respondents' minds and responses and this needed to be taken into account with further emergent drivers of behaviour.

A second driver focussed around the idea of 'employee satisfaction'. This expressed the importance of creating harmonious, respectful and dynamic working conditions which encouraged employee loyalty, creativity and the 
desire to perform to the best of one's ability (see for example, Lee, Tan and_Javalgi, 2010). Employee satisfaction relates to the 'human capital driver' which is linked to the notion of human capital management. There were a number of respondent comments from a span of belief affiliations linking employee satisfaction to the human capital driver:

'There is courtesy in treating everybody in a way that shows you appreciate their values with the organization rather than taking people for granted.'

(Respondent 12, Male, Law Firm, 26-35, Religious).

The above observation was summed up by the notion of: 'A happy staff is a more productive staff' (Respondent 5, Female, IT, 36-45, Atheist). The responses indicate the importance the interviewees ascribed to nurturing interpersonal relationships, treating a person as a 'whole' rather than at face value. The data also suggest that values and practices associated with courtesy, equality, creating the conditions for autonomy and responsibility (i.e. treating people like adults) and expressing loyalty and faith in peoples' abilities, are generally seen as creating a more coherent and cohesive corporate setting.

A third driver emerged in the form of a 'spiritual capital' driver. It highlighted the way that VBA shaped the lives of our sample, and their interactions, not only in the workplace, but also into the wider community:

'Success is based on doing things well rather than cutting corners. I sleep well at night knowing there are no skeletons in the closet. People who cut corners generally have to move on every five years there is a risk of things coming back to haunt you.' (Respondent 11, Male 65 plus, Law Firm, Religious). 
'Spent half an hour on a Saturday night standing outside my home because the signal's not very good, talking to a client - so yeah my values affect my work in that way.' (Respondent 9, Female, Law Firm, 26-35, Religious).

These employees placed great emphasis on the value of integrity and truthfulness. They expected colleagues to be trustworthy and recognise the importance of reflecting on 'mistakes' as a means to becoming a better person at work and 'all round', and they upheld the work ethic of 'going the extra mile' to get the job done. These illustrations also exemplify how spiritual capital directly effects change for the better (what we might call 'progressive change') in the wider corporate environment. The emphasis on transparency and trust reflected the importance attached to the integrity and reputation of the individuals and the companies concerned. This is a form of bonding social capital which is concerned with maintenance of the resilience of the internal bonds that sustain the company and contributes to 'intra-group linking' forms of social capital (Putnam, 2000). The emphasis on 'going the extra mile' however, expresses a degree of empathy, care and concern for a client that transcends normal protocols of engagement for the sake of an increased likelihood of a positive outcome. This expresses aspirations towards more bridging and linking forms of social capital (i.e. creating organizational horizontal and vertical forms of engagement and connection).

The fourth driver concerns the pressures exerted by external dynamics that lie beyond the control of individuals and companies, but which impact particularly on the local operational priorities of organizations (Stacey, 2010; Shaw 2010; 2012). These dynamics are most associated with, for example, globalisation and the growth in international competition on the one hand, and economic austerity on the other and in the present argument is termed the 'Global/Local' driver. The dynamics associated with the global/local nexus were deemed to be influential on business 
practice and ethics. Sometimes they impacted in ways that work against the desire to implement more responsible or sustainable working practices:

'In stripping back the costs they never focus on what do the clients want and 'Are we giving them a good service?' You kind of find that client care is pushed to the back which ultimately is going to lead to problems with the business.'

(Respondent 7, Female, Law Firm, 36-45, Religious/Spiritual).

However, other respondents' employers had different responses to the post-2008 financial crash. The manufacturing company in the survey decided to retain their skilled workforce but on much reduced time. In the meantime, its employees were encouraged to undertake maintenance and improvement jobs in the wider community. One employee recalled:

'There was not enough work so the company sent people out to churches and places like that and painting fences and basically just sending people out to do jobs. We moved to a four-day week and paid wages at $55 \%$, but on top of that there were guys volunteering to go out and do things?'

(Respondent 17, Male, Manufacturing, 26-35, Religious/Spiritual).

Taken as a whole, many of the drivers associated with spiritual capital expressed language and behaviour that valued those interventions within the corporate setting aimed at creating a sense of belonging and wellbeing. These include an awareness of the need to connect with others, demonstrate empathy and perform altruistic gestures. This expression of VBA in the workplace appears to seek to minimise, wherever possible, outcomes which are potentially harmful and distorting, and, alternatively, to create forms of bridging and linking capital that can mitigate the more negative dimensions of in-group mentality (which can be termed bonding social capital). The drivers are summarised below: 


\section{Sources of VBA}

A wide range of sources of VBA related insights emerged in the data including in the spheres of education, family values and experience, peer pressure, culture, the media, company ethos, business practices, personality, wisdom with maturity, friends, religion and spiritual values and expectations by others. Several respondents indicated that their sources of VBA emerge from a combination of these different elements. This represents a typical response:

'Personally I am not religious in any way - so it is nothing to do with that - but in my experience, it comes from a variety of mixture of things - where you come from, obviously everyone has their own personality and people handle different situations in different ways ....and the focus on good business practice - always telling the truth' (Respondent 2, Male, 18-25, IT Firm, Atheist).

A further respondent reflected: 'Certainly your upbringing, your religious beliefs, your friends, peer pressure, that type of thing has an awful lot to do with who you become I think' (Respondent 8, Female, 26-35, Law Firm, Religious).

However, the two sources of VBA that were cited most often were the confluence of culture/ethos of the company, and the respondents' family context. Company culture/ethos was viewed as both a positive and negative sources of influence on human activity. An example of positive influence emerged in the manufacturing company which employed over 200 employees from thirteen nationalities. At the heart of this company was a strong philosophical and spiritual belief in the concept of harmonisation. One interviewee described it thus: 'You harmonise with the people around you and you harmonise with the globe basically' (Respondent 13, Male, Manufacturing, 46-55, Religious). He continues, 'We British see it as like "working with each other" whereas perhaps that word 
they (the senior management) might use is more in the form of 'soft culture' Zen or whatever.' For him this explicit company ethos does have an influence on the wider working environment. 'At a pragmatic level it represents respect - you want to gain it, but you have to command respect and it has to be a two-way thing. You communicate respect in the way you speak and react to people - the way they speak back and react to you.' Examples of negative influence of company ethos were often based on painful personal experiences, which have the counter-intuitively worked to reinforce more positive work-based practices outlined above.

However, the most influential source of VBA seemed to be the family, which was a significant variable across the whole sample:

'I suppose some of my values about fairness and openness and honesty come from my mum...' (Respondent 18, Male, Manufacturing, 26-35, Religious/Spiritual).

'Yes, your belief systems, most of them, stem from your family your sense of right and wrong and what is just' (Respondent, 10, Female, Law Firm, 36-45, agnostic/atheist).

Family experience can produce progressive values and attitudes even if the contexts from which they emerged have been shaped by sadness and trauma: 'When I was younger, my mum and dad were very busy so sometimes when I got back from school and I was struggling with my homework I might ask my mum and she would show it me and because I was a bit slow like picking it up, she didn't have much patience so I had to sort it out myself' (Respondent 5, Female, IT Firm, 36-45, Atheist). This experience has created in this individual an appreciation of working as a part of team, and fostering an atmosphere where people feel supported and so can grow in confidence and flourish (Deal and Kennedy, 1982; Crane and Matten, 2010). 
For those respondents who defined themselves as religious or spiritual, clearly their religious outlook or spiritual disposition was an explicit and decisive source of VBA: 'For me, as a practising Catholic - I think I have always had the desire to help people through a difficult time' (Respondent 7, Female, Law Firm, 36-45, Religious/Spiritual). This interviewee elucidates what this belief system means in practice. 'At the end of a case when someone has been through a traumatic divorce and their life has fallen apart, you help them through and guide them. You take their hand, often literally, through the process and towards the end you see them flourish and have confidence ... for me that is special'. Another reported: 'I do have a spiritual upbringing - both my parents are Christian. It's something that is ingrained in you. But I also think that whilst you want to be religious to a certain extent, you've still got to be in a business to make money, which to me don't necessarily go together' (Respondent 4, Male, IT Firm, 26-35, Religious). For respondents who reported explicit religious influence, this surfaced as a clear VBA driver of behaviour in the workplace. One interviewee was a very senior manager in his company who was attempting to reconcile his strong religious beliefs with a strong entrepreneurial drive. One way to achieve this was to ensure that the company he worked for remained embedded in the local community from where most of the workforce was drawn: 'You are here as part of the community...':

'Two members of staff from the same family - their mum passed away last night. I said, "Take the rest of the week off". I could have said it as compassionate leave - but you have think about the impact on the community. We are here to provide economic benefit for those that live locally. Part of business is community - and we have to treat people as humans as opposed to just coming in and doing their job.'

(Respondent 17, Male, Manufacturing, 26-35, Religious/Spiritual) 
While not necessarily expressing religions, some of the interviewees had been brought up in a religious household, and they acknowledged that its influence was still present: 'Myself, I am not a religious person. My dad is a devout Catholic, but my mum is not - and I was always given a choice - do you want to go to church? I have been to all different types of churches we even went to a Mormon church when we were in school 'cos the lads were fit' (Respondent, 16, Female, Manufacturing, 36-45, Agnostic). This openness to religious identity as a child had been carried over into adult life. This interviewee saw her role as creating an atmosphere of equality and fairness amongst the different ethnic and religious groups in her workplace: "I've always been taught to say "Please" and "Thank You", and speak to somebody how I would want to be spoken to.' Another interviewee reflected on the impact of religious education: 'I went to a Catholic school so every day you were given those sort of instructions. I suppose those beliefs were instilled in you even if it was subconsciously. I was always brought up to respect other people and always never to let anyone down - always to do your best' (Respondent 17, Male, Manufacturing, 26-35, Religious/Spiritual).

\section{Impact of VBA on individual and corporate behaviour}

Some of the perceived impacts of VBA were directly related to enhancing the economic performativity of the company. Those who cited the 'bottom-line' driver, its impact on the corporate environment was expressed as 'Get the job done to be blunt really...' and 'I see projects through from start to finish' (Respondent 1, Female, IT, 18-25, Religious). However, this driver was also channelled into providing client satisfaction, even though this aspiration was often far from easy to implement. The pressure to sacrifice the needs of smaller clients for the more lucrative corporate contracts was one that required the exercise of values and attitudes associated with a sense of fairness, equality and the exercising of personal initiative. For example: 'You have a client that from a company perspective is not a massive income driver. But you have a great relationship with them - they are talking to you all the time and you enjoy 
it... but on the back of the company perspective, you are neglecting ones that are more important - there is juggling that needs to be done' (Respondent 2, Male, IT, 18-25, Atheist).

From within the manufacturing setting comes the impact of company loyalty in the face of a global downturn to enhanced worker productivity: 'We looked after our people - for the past 18 months we have been on a four-day week. But we are trying to stay together so that if we come out shining the other side, then we will have the same people here. Because we have shown loyalty to the workforce then they don't so shoddy work in fact the quality of our work has massively improved in the last two years' (Respondent 13, Male, Manufacturing, 46-55, Religious).

However, by far the greater impact generated by VBA is perceived to take place at the level of relational flourishing that might be deemed to link more closely with soft aspects of culture (reflecting Alvesson and Willmott, 2003) - this produced reflections of the ilk:

'I understand the majority of our clients do not have the technical knowledge to understand what we are talking about [in terms of web design] - so I try and put it in simple terms. I try and put myself down to their level and be very patient about it, as well as in a polite and understanding way' (Respondent 5, Male, IT Firm, 36-45, Atheist).

We can observe how the spiritual capital derived from interviewees' VBA is played out in terms of strategies of patience and empathy, thus making the clients feel affirmed and not intimidated. Where it was identified, honesty of communication that was appropriately and sensitively handled assisted in creating an atmosphere of accountability and trust.

Within the solicitor's corporate setting, we observed further impacts: the courage and integrity required to deal with aspects impacting negatively 
on VBA: 'In terms of internally, I have certainly been seeing inappropriate behaviour and turned a blind eye to it. It's so easy in life just not to look and probably better for your career. Sticking your head above the parapet has had its consequences for me because it was seen as sticking your nose in where it is not wanted' (Respondent 8, Female, Law Firm, 26-35, Religious).

Within the manufacturing setting, the following simple and universal ethic espoused by one of our interviewees has a quiet but profound impact: 'I am very aware in terms of looking after people - treat them as you would want to be treated' (Respondent 15, Male, Manufacturing, 36-45, Agnostic). This ethical principle was expressed most concretely in the idea of fairness: 'It's just about trying to be fair I suppose - how I talk to other people is how I like to think I talk to my family... I won't criticise someone for going wrong. Some managers - that's all they say. I'll try and help them instead and show them the right way of how to do it.' Thus it was evidenced that VBA infused respondents' behaviour and provided a moderating influence on organizational atmospheres and, in particular, relational tensions with bottom-line metrics and wider relational dynamics.

\section{Negotiating and Performing Religious Identities in the workplace}

When we explore the comments made by those with an explicit religious identity and/or religious/spiritual identity (i.e. 33\% of the cohort), then it is possible to detect a more explicit sense of how their VBA (as spiritual capital) directly shapes their participation within the public spaces of the corporate environment. One of the interviewees, a 'practising Catholic' reflects this process:

'You go to church on a Sunday and you are told to remember to treat people as you would want to be treated yourself and to be a good neighbour. That sort of sermon you digest and you can't achieve it all the time and you hope that is how you might emulate your relationships at work in an appropriate way and in a non- 
discriminatory fashion' (Respondent 9, Female, Law Firm, 26-35, Religious).

This attachment to the value of non-discrimination has a direct impact on this respondent's work within the legal profession:

'In terms of beliefs I would expect beliefs to be kept outside the workplace and I think that's appropriate. I go to church but I wouldn't discuss it at work unless it was something that was asked of me and I wouldn't lie about it... I wouldn't make a big issue of it and I think it is actually quite damaging.'

Meanwhile, a participant from the manufacturing cohort, who had a religious upbringing as a child, but who now defines herself as an agnostic agreed that religious belief is ultimately a private affair that has no place within the public setting of the corporate culture. However, for her, any sort of personal passion or hobby should not be shared in the workplace. 'I wouldn't go spouting off that I like watching motorbikes, and so I don't expect you to go spouting off about your religious beliefs ... it's something that is just private'.

(Respondent 16, Female, Manufacturing, 36-45, Atheist).

It would seem that for some individuals, it was difficult for them to express their religious/spiritual motivation in the professional sphere. The extent to which an employee feels comfortable expressing their religion/spirituality at work may be influenced by how s/he perceives the employer complying with legal provisions such as the Equality Act 2010. However, there is a danger that this form of state-led intervention creates an environment that fosters a lack of religious literacy (for fear of causing offence) which in turn exacerbates a need to keep the corporate space focused on a utilitarian and secular level (Dinham and Francis, 2015) In summary, the research shows that respondents are open and persistent in identifying new and 'intuitive' ways to express their spiritual and VBA 
identities because not to do this further disconnects who they really are from the work-based setting.

The four themes which emerge from the analysis, and their underpinning data, provide a rich and nuanced picture concerning the relationship of VBA (as spiritual capital) to other forms of capital such as human capital, social capital and therefore economic capital. We have summarised these themes diagrammatically. At the heart of these data lies a potentially mutually reinforcing (or virtuous) process of capital production (as indicated by the circular flow of the arrows) that is produced by the dynamic interplay between the four drivers outlined earlier set against a backdrop dialectic of modernistic-critical and commensurate hard-soft approaches to managing and organizing. This interplay creates contributions that transcend material forms of capital to engage with bridging and linking (i.e. relational) forms of social capital. This generates enhanced employee satisfaction and a perceptible contribution to social solidarity that helped bridge private and professional divides (thus contributing to human capital) - see Figure 1.

\section{INSERT FIGURE 1 HERE.}

The findings of the present research build on the definitional and exploratory literature work conducted in earlier papers (Authors, 2011). The research has empirically explored and modelled the definitions and earlier literature assertions surfacing the drivers, sources and impact of VBA in organizational settings. Moreover, it has provided insights and structures relating to human, social and spiritual capitals illustrating how social and spiritual capitals interact with organizational bridging and linking capitals that inform and modify the hegemonic modernistic human capital structures towards meaningful and less mechanistic ends. 


\section{Conclusions}

Building on earlier definitional work and literature examinations on VBA (Authors, 2011), the present paper has undertaken an exploration of the relationship and interconnections between human, social and spiritual capitals. This was undertaken through the construction of a theoretical modernistic-critical framework situating human capital as a predominantly modernistic device and pointing up social and spiritual capitals as moderating and adjusting forces to the mechanistic nature of modernistic approaches. Furthermore, within the application to the organizational context, the argument invoked the notion of bridging and linking capitals which facilitate the interconnection of other capitals within the overall structure. In addition, the above work has been accomplished by an interdisciplinary team fusing religious and theological perspectives within a critically informed management and organizational perspective.

First, VBA makes an often hidden, even mundane, but also very powerful, contribution to human capital. It potentially enhances the value of every member of the company by creating additional conditions and dimensions in which their 'knowledge, capabilities and skills' can be better expressed, thus enhancing their sense of emotional wellbeing and job satisfaction, which in turn minimises the more destructive and inimical practices that were highlighted within the corporate setting. In this way the softer aspects of the corporate culture infuse, inform and provide a 'lubricant' and mitigating factor for the more regressive aspects of strong or hard dimensions of culture.

Second (and linked to the point above), the drivers and application of VBA can be seen to have a multi-levelled impact: from the smallest attention to detail that makes an employee feel valued and noticing another's struggles and engaging empathically, through to standing up of the underdog in the face of perceived mis-management or corruption within the structures of the business. Occasionally, VBA highlights the role of 
business as part of a wider web of interconnectedness that directly connects with global ethical agendas concerning, for example, the wellbeing of the planet as a whole.

Third, the study highlighted the highly skilled and nuanced way in which these values, beliefs and attitudes were performed and negotiated within often rigid and bureaucratic management and production systems. This allowed many 'soft' cultural aspects to humanise the business environment and prompt changes in individual behaviour and company policy. This augers scope for further studies in relation to, for example, agility, flexibility and ambidexterity and VBA in additional attempts to explore the dialectical implementation across modernistic-critical and hard-soft cultural boundaries.

Fourth, that despite (or perhaps because of) the heightened awareness of the role and presence of religion and spirituality in the corporate sphere, those within the survey who identified as religious or strongly spiritual felt that the 'why' or motivation generated by their VBA should continue to remain hidden from public view. This emerges as a key issue and challenge for the negotiation of personal and professional boundaries. Influential commentators like Jürgen Habermas for example, are clear that within the auspices of a liberal democratic state, it is profoundly illiberal and undemocratic to demand that religion citizens occlude or moderate their core identities in the public sphere in ways that are not expected of those who define themselves as not religious (2005). A question worth pursuing is to what extent this self-censorship is self-imposed, or comes about through a perceived residual hostility to religion? Or does the corporate environment in the UK represent an ongoing modernistic and 'hard' cultural tendency for a 'one-size fits all' view of the public sphere, whereby only the secular is perceived as neutral and therefore eligible for public consumption, and the religious is deemed fit only for private expression (but see also the provision of prayer rooms for staff in many UK firms which contrasts favourably with other EU settings, such as in 
France where work and religion are considered incompatible (Euzen, 2013).

The findings suggested by the data are perhaps counter-intuitive to this last point. They suggest that the more businesses can be open to acknowledging the existence of both religious and secular expressions of spiritual capital the more humane and therefore the more productive their corporate environment is likely to be. The more spaces and places in which staff can be facilitated to express their deepest values, beliefs and attitudes for positive change and the well-being, then the more authentically connected they will feel to the roles that have been assigned to them.

The research thus presents a number of managerial and organizational implications in relation to spiritual capital (and related capitals). Managers of organizations and their employees need to remain, or even enhance, their awareness of the potential contribution of recognising spiritual capital in the work setting. There is a persistent danger that a tendency by managers to lean back almost exclusively on modernistic, 'hard', human capital managerialist-style approaches will not necessarily deliver the desired performative organization. There is a need to complement, and sometimes subvert, modernistic stances with critical, 'soft' approaches that provide a role and space for social and spiritual capitals to be propagated, and infused within, the organization. Equally, there is a need for management and organizations to acknowledge the role of bridging and linking capitals in facilitating the operation of other capitals within the organization.

Finally, in relation to findings, three limitations to this analysis should be acknowledged. First, due to the geographic regional focus of the study, the data derived were predominantly of Christian, rather than alternative, denomination. Second, the data set for the study is relatively small (thus allowing in-depth data collection and analysis). However this is a further 
factor limiting generalisation and pointing up the need for further wider studies. And, third, the study was conducted in a Northern UK context and therefore exhibits socio-political-cultural characteristics of that region which are likely to differ from an alternative context.

\section{Future Research Directions}

The study points the way towards a need for a new business model that instils a strategic agenda of VBA-underpinned well-being at work for employees, more than merely paying lip-service to many current approaches and legislation. Moreover there is scope to expand the study by placing the focus on a different social groups: non-employed individuals; cross-generational or gender/sexuality based studies to compare the express and practical impact of VBA in the corporate setting; longitudinal surveys that correlate self-reported increases of VBA amongst individuals working for a company and any variations in key business success indicators such as worker retention, increased outputs, more effective strategy and leadership. Moreover, transcontinental surveys that compare how wider religio-cultural norms affect corporate business practice and outputs (for example Islam on growing Islamic economies such as Indonesia and Malaysia, Hinduism on India, Buddhism (as mindfulness) on UK and European business practices as well as S.E Asian economies, Daoism and Confucianism on China provide a range of exciting possible directions. 


\section{References}

Alvesson, M. (2002). Understanding Culture, London, Sage Publications.

Alvesson, M. \& Willmott, H. (2003). Studying Management Critically, London, Sage Publications.

Ashkanasy, N., Härtel, C. and Zerbe, W. (2012) Research on Emotions in Organizations (Vol. 8): Experiencing and Managing Emotions in the Workplace, Bingley, Emerald Publishing.

Authors (2011)

Badham, R., Garrety, K., Morrigan, V., Zanko, M. \& Dawson, P. (2003). Designer Deviance: Enterprise and Deviance in Culture Change Programmes. Organization, 10(4): 707-730.

Baker, C. (2012) 'Spiritual Capital and Economies of Grace - Refining the Relationship between Religion and the Welfare State', Social Policy and Society, 11(4): 565-576

Baker, C. \& Skinner, H. (2006). Faith in Action: The Dynamic Connection between Spiritual and Religious Capital. Manchester: William Temple Foundation.

Baker, C. and Miles-Watson, J. (2008). Exploring Secular Spiritual Capital; An Engagement in Religious and Secular Dialogue for a Common Future, International Journal of Public Theology, 2(4): 442-464.

Barros, C. P. (2006). Earnings, schooling and social capital of cooperative managers. Annals of Public \& Cooperative Economics. 77(1):1-20.

doi: $10.1111 / j .1370-4788.2006 .00295$

Berger, P. (1973). The Social Reality of Religion, Harmondsworth, Penguin.

Berger, P. (1999). The Desecularization of the World - Resurgent Religion ad World Politics, Grand Rapids, Eerdemans Publishing.

Blowfield, M. and Murray, A. (2011). Corporate Responsibility, Oxford, Oxford University Press.

Bourdieu, P. (1997). The Forms of Capital, in: A. Halsey, H. Lauder, P. Brown \& A. Stuart Wells (Eds.) Education: Culture, Economy and Society, Oxford: Oxford University Press.

Burton-Jones, A. and Spender J-C. (2012) The Oxford Handbook of Human Capital, Oxford, Oxford University Press. 
Brammer, S. J., and S. Pavelin (2013). "Corporate governance and corporate social responsibility." The Oxford handbook of corporate governance: 719-743.

Caryl, C. (2013). Strange Rebels: 1979 and the Birth of the $21^{\text {st }}$ Century, Basic Books, New York.

Casanova, J. (1994). Public Religions in the Modern World, Chicago, University of Chicago Press.

Clegg, S, Kornberger, M. and Pitsis, T. (2005). Managing and Organizations: An Introduction to Theory and Practice, London, Sage Publications.

Cloke, P., and Beaumont, J. (eds.) (2012). Faith-based organisations and exclusion in European Cities, Bristol, Policy Press.

Crane, A. \& Matten, D. (2010). Managing Corporate Citizenship and Sustainability in the Age of Globalization, Oxford, Oxford University Press.

Dess, G. G. \& J. D. Shaw (2001). Voluntary turnover, social capital and organizational performance, Academy of Management Review, 26, pp.446-4.

Dinham, A., Furbey R. \& Lowndes V. (eds.) (2009). Faith in the Public Realm: Controversies, Policies and Practices, Bristol: Policy Press,

Euzen, Philippe (2013) Entreprises et religion, comment faire? Le Monde [online] April $1^{\text {st }}$. Available at:

http://www.lemonde.fr/idees/article/2013/04/01/entreprises-et-religioncomment-faire 3150394_3232.html [accessed 01 December 2014].

Field, J. (2003). Social Capital, London and New York, Routledge.

Fineman, S. (2000). Emotion in Organizations, London, Sage Publications.

Gabriel, Y. (2000). Storytelling in Organizations: Facts, Fictions and Fantasies, Oxford, Oxford University Press.

Gabriel, Y. (2004). Myths, Stories and Organizations: Pre-Modern Narratives for Our Times,

Oxford University Press, Oxford.

Gabriel, Y., \& Lang, T. (2006). The Unmanageable Consumer, London: Sage Publications.

Halpern, D. (2005). Social Capital, Cambridge, Polity Press. 
Hitt, M. A. \& R. D. Ireland (2002). The essence of strategic leadership: managing human and social capital, Journal of Leadership and Organizational Studies, 9: 3-14.

Gilbert, P. (2011). Spirituality and Mental Health - A handbook for service users, carers and staff wishing to bring a spiritual dimension to mental health, Brighton, Pavilion Press.

Habermas, J. (1986). The Theory of Communicative Action - Reason and the Rationalisation of Society - Volume 1, Cambridge, Polity Press.

Habermas, J. (2006). Religion in the public sphere. European Journal of Philosophy 14(1): 1-25.

Hartog, J. and Maassan Van der Brink, H. (2009) Human Capital: Advances in Theory and Evidence, Cambridge. Cambridge University Press.

Hatch, M-J. (2013). Organization Theory: Modern, Symbolic and Postmodern Perspectives, Oxford, Oxford University Press.

Holloway, M. (2005). In the Spirit of Things: Social Work, Spirituality and Contemporary Society, Inaugural Lecture at the University of Hull, UK (10 October 2005).

Jeanes, E. and Huzzard, T. (2014) Critical Management Research: Reflections from the Field, London, Sage Publications.

Jermier, J., Knights, D. \& Nord, W. (1994). Resistance and Power in Organizations, London, Routledge.

Joshua, J. (2015) The Contribution of Human Capital Towards Economic Growth in China, Basingstoke, Palgrave Macmillan.

Kaufman, N. A. \& Geroy, G. O. (2007). An Energy Model for Viewing Embodied Human Capital Theory, Performance Improvement Quarterly, 20 (1): 37-48.

King, N. (2004a). 'Using Interviews in Qualitative Research' in Cassell, C and Symon, G. (2004) Essential Guide to Qualitative Methods in Organizational Research, London, Sage Publications, pp.11-22.

King, N. (2004b). 'Using Templates in the Thematic Analysis of Text' in Cassell, C. and Symon, G. (2004) Essential Guide to Qualitative Methods in Organizational Research, London, Sage Publications, pp.256-270.

King, N., and Horrocks, C. (2010). Interviews in Qualitative Research, London, Sage Publications 
Knights, D. and Willmott, H. (2012). Introducing Organizational Behaviour Management, Andover, Cengage Learning.

Lawrence, S. and Jordan, P. (2009). Testing an Explicit and an Implicit Measure of Motivation, International Journal of Organizational Analysis, 17(2): 103-120.

Lee, O, Tan, J. \& Lavalgi, R. (2010). Goal orientation and organizational commitment: Individual difference predictors of job performance, International Journal of Organizational Analysis, 18(1):129 - 150.

Lee, S. Lovelace, K and Manz, C. (2013). Serving with spirit: an integrative model of workplace spirituality within service organizations, Journal of Management, Spirituality and Religion, 11(1): 45-64.

Leitch, C. M., McMullan, C. \&Harrison, R. T. (2013). The Development of Entrepreneurial Leadership: The Role of Human, Social and Institutional Capital, British Journal of Management, 24(3): 347-366.

Lin, N., K. Cook and R. S. Burt (eds) (2001). Social Capital: Theory and Research. New York: Aldine de Gruyter.

Linstead, S. Fulop, L. and Lilley, S. (2009). Management and Organization: A Critical Text, Basingstoke, Palgrave-Macmillan.

Liviu, F., Cheung, Y. and Herndon, N. (2013). For all good reasons: Role of values in organizational sustainability. Journal of Business Ethics 114(3): 393-408.

McDowall, A and Saunders, M (2010) 'UK managers conceptions of training and development', Journal of European Industrial Training, 34(7) 609-630.

Micklethwaite, J. and Wooldridge, A. (2009). God is Back - How the Global Rise of Faith is Changing the World, London, Penguin.

Morgan, G. (2006). Images of Organisation, Thousand Oaks, Sage.

Putnam, R. (2000). Bowling Alone - The Collapse and Revival of American Community, New York: Simon and Schuster

Rishi, P. \& Moghe, S. (2013) “Integrating Corporate Social Responsibility and Culture as a Strategy for Holistic Corporate Success in India" Journal of Corporate Citizenship, 51: 17-37.

Smith, W., Singal, M. \& Lamb, W. (2008). Corporate social orientation in Japan and the USA: a cross-cultural comparison, International Journal of Organizational Analysis, 15 (3): 181-209. 
Sandel, M. (2012). What Money can't Buy - The Moral Limits of Markets London, Penguin.

Sandercock, L. (2008). Spirituality and the Urban Professions: The Paradox At the Heart of Urban Planning, Planning Theory and Practice, 7 (1): 69-75.

Shaw, P. (2010). Defining Moments: Navigating through Business and Organizational Life, Basingstoke, Palgrave Macmillan.

Shaw, P. (2012). The Age of Agility, London, Praesta Partners.

Silver, C. (2013). Studying Non-Belief http://www.atheismresearch.com/ (retrieved December 9, 2014)

Skidelsky, R and Skidelsky, E. (2012). How much is Enough - Money and the Good Life, London, Penguin.

Stacey, R. (2010). Complexity and Organizational Reality: Uncertainty and the Need to Rethink Management after the Collapse of Investment Capitalism, London, Routledge.

Stokes, P. (2011). Critical Concepts in Management and Organization Studies, Basingstoke, Palgrave-Macmillan.

Tenhiälä, A., Linna, A., von Bonsdorff, M., Pentti, J., Vahtera, J., Kivimäki, M., \& Elovainio, M. (2013). Organizational justice, sickness absence and employee age. Journal of Managerial Psychology, 28 (7/8), 805-825.

doi:10.1108/JMP-07-2013-0246

Tweed, T. (2006). Dwelling and Crossing - A Theory of Religion, Cambridge, MA, Harvard University Press.

Urry, J. and Larsen, J. (2011). The Tourist Gaze 3.0, London, Sage Publications.

Vasquez, M. (2011). More than Belief - A Materialist Theory of Religion, Oxford, Oxford University Press.

Waring, T and Wainwright, D. (2008) Issues and challenges in the use of template analysis: Two comparative case studies from the field', The Electronic Journal of Business Research Methods, 6(1): 85-94.

Woolcock, M. (2001). "The Place of Social Capital in Understanding Social and Economic Outcomes" ISUMA Canadian Journal of Social Research 2 (1): 11-17.

Zohar, D. \& Marshall, I. (2004). Spiritual Capital: Wealth We Can Live By. Berrett-Koehler Publishers, San Francisco. 


\begin{tabular}{|c|c|}
\hline $\begin{array}{l}\text { Modernistic bottom-line or } \\
\text { metrics driver } \\
\text { (capital as forms of income): } \\
\end{array}$ & $\begin{array}{l}\text { Employee satisfaction } \\
\text { (human capital) modernistic- } \\
\text { critical interface and drivers: } \\
\text { - Importance of creating harmonious } \\
\text { and working conditions } \\
\text { - encouraging employee loyalty, } \\
\text { creativity and the desire to perform } \\
\text { to the best of their ability } \\
\text { - A happy staff is a more productive } \\
\text { staff' }\end{array}$ \\
\hline $\begin{array}{l}\text { Global/local nexus of } \\
\text { modernistic-critical/soft-hard } \\
\text { interfaces set against } \\
\text { national religious-cultures } \\
\text { (Capital on a global corporate } \\
\quad \text { scale): } \\
\text { Concerns about } \\
-\quad \text { International competition } \\
-\quad \text { Global/local nexus } \\
-\quad \text { Exploitation of low-paid workers in } \\
\text { - ther countries } \\
\text { - Taking on cheaper and less-qualified } \\
\text { - } \text { labour } \\
\text { Reduction in client satisfaction }\end{array}$ & 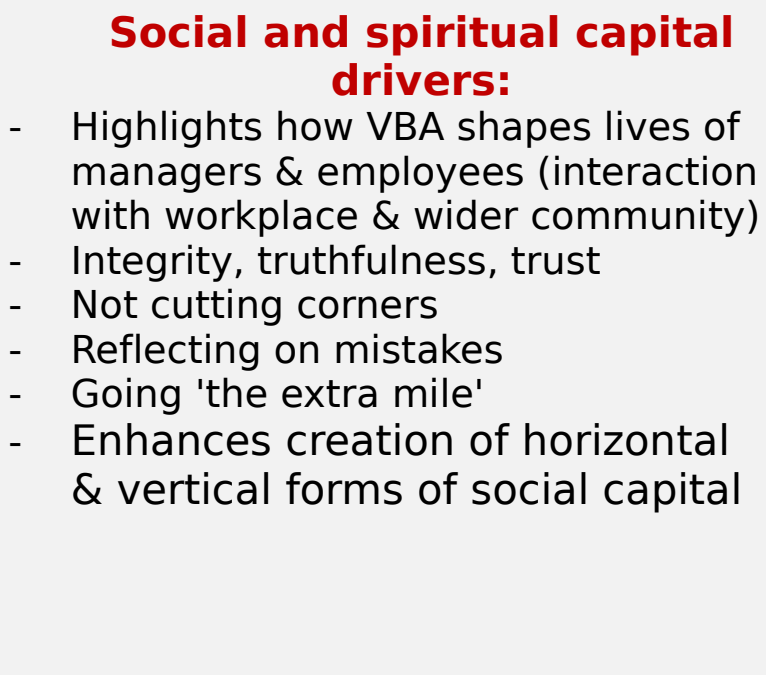 \\
\hline
\end{tabular}

Figure I: Summary of interrelated VBA and capitals that shape everyday postsecular organizational culture: drivers, sources, impacts, interfaces and pathways.

(The diagram legends indicate the micro-impacting and the macroimpacting forms of capital, flows and ways in which the factors of 'bottom line', employee satisfaction, spiritual capital and the global nexus interact 
in an interactive manner around, and through, spiritual capital and cites data as exemplars of particular drivers in operation.) 
Figure I: Summary of interrelated VBA and capitals that shape everyday postsecular organizational culture

(The diagram legends indicate the micro-impacting and the macro-

impacting forms of capital, flows and ways in which the factors of 'bottom line', employee satisfaction, spiritual capital and the global nexus interact in an interactive manner around, and through, spiritual capital.)

Macro-impacting on linking \& bridging capitals

Impacting in myriad micro-ways to linking and bridging

Impacting in myriad macro-ways to linking and bridging

Micro-impacting on linking $\&$ bridging capitals

Bottom line or metrics driver

(capital as forms of income):

Global/local nexus

(Capital on a corporate scale):

Employee satisfaction (human capital) driver:

Spiritual capital driver: 
THE INDIVIDUAL WITHIN THE ORGANISATION

(linking \& bridging capitals)

Table 1 Self-Reported Data Respondent Profiles

\begin{tabular}{|c|c|c|c|c|c|}
\hline $\begin{array}{l}\text { Respondent } \\
\text { Organization }\end{array}$ & $\begin{array}{l}\text { Respondent } \\
\text { Role }\end{array}$ & $\begin{array}{l}\mathbf{M} / \\
\mathbf{F}\end{array}$ & Age & $\begin{array}{l}\text { Whit } \\
\text { e } \\
\text { Briti } \\
\text { sh }\end{array}$ & $\begin{array}{l}\text { Lickert Scale: } \\
1=\text { strong... } \\
5=\text { not strong at all }\end{array}$ \\
\hline \multicolumn{6}{|l|}{$\begin{array}{l}\text { IT/Internet } \\
\text { Firm }\end{array}$} \\
\hline 1 & $\begin{array}{l}\text { IT Department } \\
\text { Manager }\end{array}$ & $\mathrm{F}$ & $\begin{array}{l}18- \\
25\end{array}$ & $\bar{Y}$ & $\begin{array}{l}\text { 1 Religious, } 2 \text { Spiritual, } \\
3 \text { Agnostic, } 4 \text { Atheist }\end{array}$ \\
\hline 2 & IT Analyst & $M$ & $\begin{array}{l}18- \\
25\end{array}$ & $\bar{Y}$ & $\begin{array}{l}5 \text { Religious, } 5 \text { Spiritual, } \\
2 \text { Agnostic, } 1 \text { Atheist }\end{array}$ \\
\hline 3 & HR Manager & $\mathrm{F}$ & $\begin{array}{l}36- \\
45\end{array}$ & $\mathrm{Y}$ & $\begin{array}{l}1 \text { Religious, } 1 \text { Spiritual } \\
4 \text { Agnostic, } 2 \text { Atheist }\end{array}$ \\
\hline 4 & CEO & $M$ & $\begin{array}{l}26- \\
35\end{array}$ & $\mathrm{Y}$ & 2 Religious \\
\hline 5 & \begin{tabular}{|l} 
Website \\
Designer
\end{tabular} & $\mathrm{F}$ & $\begin{array}{l}36- \\
45\end{array}$ & $\mathrm{Y}$ & 1 Atheist \\
\hline 6 & $\begin{array}{l}\text { Website } \\
\text { Designer }\end{array}$ & $\mathrm{F}$ & $\begin{array}{l}18- \\
25\end{array}$ & $\mathrm{Y}$ & 5 Agnostic \\
\hline \multicolumn{6}{|l|}{ Law Firm } \\
\hline 7 & $\begin{array}{l}\text { Solicitor - } \\
\text { Business } \\
\text { Manager }\end{array}$ & $\mathrm{F}$ & $\begin{array}{l}36- \\
45\end{array}$ & $\bar{Y}$ & $\begin{array}{l}1 \text { Religious, } 1 \text { Spiritual, } \\
5 \text { Agnostic, } 5 \text { Atheist }\end{array}$ \\
\hline 8 & $\begin{array}{l}\text { Solicitor - } \\
\text { Business } \\
\text { Manager } \\
\end{array}$ & $\mathrm{F}$ & $\begin{array}{l}26- \\
35\end{array}$ & $\bar{Y}$ & $\begin{array}{l}2 \text { Religious, } 1 \text { Spiritual, } \\
3 \text { Agnostic, } 4 \text { Atheist }\end{array}$ \\
\hline 9 & Solicitor & $\mathrm{F}$ & $\begin{array}{l}26- \\
35\end{array}$ & $\bar{Y}$ & 3 Religious \\
\hline 10 & Secretary & $\mathrm{F}$ & $\begin{array}{l}36- \\
45\end{array}$ & $\mathrm{Y}$ & $\begin{array}{l}5 \text { Religious, } 5 \text { Spiritual, } \\
1 \text { Agnostic, } 1 \text { Atheist }\end{array}$ \\
\hline 11 & Solicitor & $M$ & $65+$ & $\mathrm{Y}$ & $\begin{array}{l}1 \text { Religious, } 3 \text { Spiritual, } \\
4 \text { Agnostic, } 4 \text { Atheist }\end{array}$ \\
\hline 12 & Marketing & $M$ & $26-$ & $\mathrm{Y}$ & 2 Religious, 4 Spiritual, \\
\hline
\end{tabular}




\begin{tabular}{|c|c|c|c|c|c|}
\hline & Manager & & 35 & & 4 Agnostic, 3 Atheist \\
\hline \multicolumn{6}{|l|}{$\begin{array}{l}\text { Manufacturing } \\
\text { Firm }\end{array}$} \\
\hline 13 & $\begin{array}{l}\text { Assembly } \\
\text { Operative } \\
\end{array}$ & $\mathrm{M}$ & $\begin{array}{l}46- \\
55\end{array}$ & $\overline{\mathrm{Y}}$ & 1 Religious \\
\hline 14 & Supervisor & $\mathrm{M}$ & $\begin{array}{l}36- \\
45\end{array}$ & $\bar{Y}$ & $\begin{array}{l}1 \text { Religious, } 3 \text { Spiritual, } \\
1 \text { Agnostic, } 1 \text { Atheist }\end{array}$ \\
\hline 15 & $\begin{array}{l}\text { Assembly } \\
\text { Operative }\end{array}$ & $M$ & $\begin{array}{l}36- \\
45\end{array}$ & $\mathrm{Y}$ & 3 Agnostic \\
\hline 16 & $\begin{array}{l}\text { Assembly } \\
\text { Operative }\end{array}$ & $\mathrm{F}$ & $\begin{array}{l}36- \\
45\end{array}$ & $\bar{Y}$ & $\begin{array}{l}4 \text { Religious, } 3 \text { Spiritual, } \\
5 \text { Agnostic, 1, Atheist }\end{array}$ \\
\hline 17 & \begin{tabular}{|l} 
HR Manager \\
\end{tabular} & $\mathrm{M}$ & $\begin{array}{l}26- \\
35\end{array}$ & $\overline{\mathrm{Y}}$ & $\begin{array}{l}1 \text { Religious, } 1 \text { Spiritual, } \\
3 \text { Agnostic, } 3 \text { Atheist }\end{array}$ \\
\hline 18 & $\begin{array}{l}\text { Assembly } \\
\text { Operative }\end{array}$ & $M$ & $\begin{array}{l}26- \\
35\end{array}$ & $\bar{Y}$ & $\begin{array}{l}2 \text { Religious, } 2 \text { Spiritual, } \\
3 \text { Agnostic, } 3 \text { Atheist }\end{array}$ \\
\hline
\end{tabular}

Data Respondent Profiles

Respondent Organization

Respondent Role

Legal/Solicitor Partnership

IT/Internet Firm

Manufacturing Firm 